\title{
Un Mensaje Político de los Mitos la Mitología de Privación en Oaxaca, México y América Latina
}

\author{
Miguel Alberto Bartolomé ${ }^{1}$ \\ Instituto Nacional de Antropología e Historia de México, Oaxaca, México \\ E-mail: barbar2@prodigy.net.mx
}




\section{Resumen}

Este ensayo trata de un tipo particular de reflexión simbólica que he identificado como común a todos los pueblos nativos de América Latina. Es la que denomino mitología de privación, la que forma parte de la que llamo mitología del contacto, ya que ambas constituyen géneros míticos resultantes del contacto y el conflicto interétnico. Para su análisis parto de la premisa de que los sistemas simbólicos se alimentan de las culturas vividas y que las narraciones míticas condensan sistemas de significados que permiten aproximarnos a las vidas de sus creadores, en este caso signadas por la pobreza. Aquí no me importará tanto determinar cómo los símbolos dialogan entre sí o su relación con supuestas formas de pensar, sino cómo forman parte de la tarea humana de construcción de universos, de estructuras de sentido de culturas y situaciones concretas. Tal es que me propongo en estas páginas que comienzan con el estudio de los pueblos de mi lugar de trabajo y residencia, el estado mexicano de Oaxaca, y que se extienden a México y América Latina.

Palavras-chave:Mitología. Contacto Interétnico. Pueblos Indígenas. Simbolismo.

\section{Abstract}

This essay deals with a particular kind of simbolic reflexion that I have identified as being common to all the natives peoples of Latin America. I call it mythology of privation, and is part of what I have called mythology of contact, given that both constitute mythical genres product of inter-ethnic contact and conflict. For its analysis I assume the premis that symbolic systems are fed by lived cultures and that mythical narratives condense systems of meaning that allow us an aproximation to the lives of their creators, in this case marked by poverty. I will be less concerned with how symbols relate to each other, or their relation with supposed forms of thought, rather I deal with how they constitute a part of the human enterprise of construction universes, structures of meaning of concrete cultures in concrete situations. This is the task I propose in these pages, beging with the study of the peoples of my workplace and residence, in the mexican state of Oaxaca, then extending myself to Mexico and Latin America.

Keywords: Mythology. Inter-ethnic Contact. Indigenous Peoples. Symbolism. 


\section{Introducción}

Duede parecer extraño que un ensayo sobre un aspecto tan significativo de las cosmologías indígenas como es la mitología, comience con una referencia a la pobreza material relativa de sus creadores, pero sin ella se haría incomprensible la lectura que propongo, ya que es la que otorga sentido a un tipo particular de reflexión simbólica que he identificado como común a todos los pueblos nativos de América Latina. Esta es la que denomino mitología de privación, la que forma parte de la que llamo mitología del contacto, ya que ambas constituyen géneros míticos resultantes del contacto y el conflicto interétnico ${ }^{2}$. Para su análisis parto de la premisa de que los sistemas simbólicos se alimentan de las culturas vividas y, desde mi punto de vista, las narraciones míticas condensan sistemas de significados que permiten aproximarnos a las vidas de sus creadores, en este caso signadas por la pobreza, aunque ello no implique una relación mecánica sino una compleja vinculación dialéctica sujeta a múltiples mediaciones y transformaciones. Esto no se aplica, obviamente, a los mitos migratorios que pueden transmitirse de un grupo a otro, sin guardar relación directa con sus sistemas organizativos. Pero no comparto la propuesta estructuralista y posestructuralista (vide Descola, 20012 [2005]) de que las formas simbólicas tengan una vida casi independiente a la de sus creadores, ya que remitirían a un supuesto tipo especial de formas de pensamiento derivadas de un exclusivismo ontológico homogeneizante. Aquí no me importará tanto determinar cómo los símbolos dialogan entre sí o su relación con supuestas formas de pensar, sino cómo forman parte de la labor humana de construcción de universos, de estructuras de sentido de culturas y situaciones concretas. Tal es la 
tarea que me propongo en estas páginas que comienzan con el estudio de los pueblos de mi lugar de trabajo y residencia, el estado mexicano de Oaxaca, y que se extienden a México y América Latina.

En más de una ocasión he señalado que Oaxaca, el mayor ámbito multiétnico de México, constituye un verdadero laboratorio social para la experiencia de la convivencia humana (M. Bartolomé y A. Barabas, 1984; M. Bartolomé, 2008a). Sus pueblos nativos pertenecen en su totalidad a la tradición civilizatoria mesoamericana, por lo que tienen elementos materiales e ideológicos compartidos, así como otros surgidos dentro de sus propias trayectorias históricas milenarias. Se trata de procesos en los que la diacronía y las dinámicas económicas, políticas y culturales específicas, involucran a 14 configuraciones etnolingüísticas autóctonas singulares. Aparte de los orígenes e influencias culturales mesoamericanas comunes a todas ellas, también las configuraciones están todas socialmente unificadas por haber sufrido primero el colonialismo hispano y después el neocolonialismo del estado nación. Sin embargo cada una de ellas, y en muchos casos algunos de sus sectores regionales, han reaccionado de manera diferente a la imposición de un sistema externo de dominación. Históricamente se han registrado confrontaciones bélicas, negociaciones políticas, rebeliones armadas, movimientos mesiánicos, milenarismo, reivindicaciones campesinas y más recientemente las movilizaciones etnopolíticas que plantean tanto demandas autonómicas, como un mayor acceso a los recursos equivalentes a los que disfrutan otros grupos sociales. Este mismo proceso ha tenido y tiene lugar en todo México, con distintas expresiones locales que van desde la insurgencia de los mayas del EZLN (Ejército Zapatista de Liberación Nacional) a partir de 1994, en Chiapas, hasta la autonomía de hecho que ejercen (2014) algunos grupos como los llamados "caracoles" zapatistas de los mayas chiapanecos o los antiguos cazadores seris de Sonora.

El común denominador, para todo México, es que los llamados Pueblos Originarios registran mayor nivel de pobreza que el resto de la población, ya que el $80 \%$ de los indígenas son pobres y alrededor del $28 \%$ afronta precariedad alimentaria (Consejo Nacional de Evaluación Política Social, CONEVAL, 2012). La situación de Oaxaca es peor a la del resto de la población nacional, ya que la pobreza multidimensio- 
nal afecta al 62\% de la población (2 200000 personas) y el 31\% se encuentra en situación de precariedad alimentaria (más de 1.200000 personas, CONEVAL, 2013). Sólo un $9.4 \%$ de los habitantes del Estado se podrían considerar no pobres y no vulnerables, lo que nos daría un 90\% de pobreza generalizada. Y en lo que atañe a América Latina los estudios y reportes realizados por el Banco Mundial (2006), la Comisión Económica para América Latina (2006), la FLACSO (Cidanamore et al., 2006) o las Naciones Unidas, nos sitúan ante panoramas sociales signados por la precariedad y la miseria definitivamente ligadas a la condición étnica, ya que se estima que, al igual que en México, el $80 \%$ de los indígenas viven bajo la línea de pobreza. En todos nuestros países ser indio es sinónimo de ser pobre. Oaxaca no es entonces una excepción sino la expresión de un contexto económico común a todos los pueblos indígenas de México y de América Latina. Es por ello que este ensayo puede referirse a toda la población indígena del subcontinente, a pesar de las múltiples diferencias históricas, políticas y culturales existentes.

La pobreza compartida constituye así un factor unificador para más de 50 millones de personas nativas en América Latina y que trasciende la rica diversidad cultural propia de las distintas tradiciones civilizatorias de la que provienen. Estos factores unificadores, el colonialismo y la pobreza, signados por la presencia de un otro extranjero y dominador, irreductible al nosotros, son un denominador común que condiciona el desarrollo de una reflexión social en todas las culturas, que trata de explicar esas presencias y esas situaciones que no existieron siempre en sus historias. Es así que, a pesar de las diferencias, en todas ellas se han producido procesos ideológicos que trataban y tratan de encontrar un origen y un sentido para la situación por la que han atravesado históricamente. Los sistemas interétnicos históricos que involucraron a los Indígenas han provocado una serie de respuestas simbólicas que oscilaron desde el total rechazo, hasta estrategias de tipo adaptativo, tales como los sincretismos y la reinterpretación de lo occidental en términos indígenas. De este segundo tipo de fenómeno forma parte la que he llamado mitología de contacto, entendida como narrativas sobre el contacto interétnico que, a pesar de referirse 
a una nueva realidad, se encuentran íntimamente relacionadas con la mitología y cosmología tradicionales (ver nota 2). La lógica de los relatos es lo que permite, como veremos, señalar que la construcción narrativa está elaborada con base en la mitología tradicional: ésta constituye el sustrato sobre el cual se elabora el nuevo discurso, que mantiene la misma estructura formal y simbólica que aparece en la mitología preexistente. Ante la transformación de la realidad social, se produce una dinámica simbólica que elabora lo nuevo con base en el antiguo código. La reflexión anterior supone la propuesta de una lectura específica de las narraciones míticas que no está desvinculada de la tradición preexistente en etnología, tal como lo trataré de exponer a continuación.

\section{Una Lectura de los Mitos}

El mito es un relato y por lo tanto forma parte del orden del discurso, pero no debemos asumir que es un discurso cerrado, inmutable, pronunciado de una vez y para siempre, ya que a menos que un pueblo se extinga física o culturalmente sus discursos nunca se cierran (C. Lévi-Strauss, 1968a:17). La narración mítica no construye, ordena, relata y transmite algo dado que permanece y es inmodificable, ya que no es raro que busque nombrar las nuevas realidades por las que transita una cultura. No existe así una versión única de un relato sino que las versiones y modificaciones dependerán de los narradores y de sus cambiantes contextos históricos. Y para entender el carácter vivencial y sagrado de estos mismos relatos resulta conveniente tomar en consideración la perspectiva desarrollada por Mircea Eliade (1967,1972), para quien el mito es el modelo ejemplar para las conductas humanas, pero modelo cuya característica esencial es proponer una normatividad sagrada ${ }^{3}$. El mito representa así el fundamento ontológico de lo real, en la medida que lo que una cultura define como su realidad, sólo cobra un sentido trascendente en tanto se vincula con la legitimidad sagrada, con un orden significativo posible que le ofrecen los relatos de los mitos que forman parte de su cosmología.

No me adhiero al estructuralismo, mis posiciones teóricas se orientan por un eclecticismo que trata de hacer compatibles posturas 
muy diversas. Pero creo que fue a la aventura estructuralista leviestraussiana a la que le correspondió el intento de re-fundar una ciencia de la mitología, a partir de la formulación de que el mito es lenguaje, pero que al mismo tiempo está más allá del lenguaje (Lévi-Strauss, 1968a:189-90). Sus grandes unidades constitutivas, que se "despegan" del fundamento lingüístico, serían los mitemas, configurados como grupos haces de relaciones que se organizan como núcleos de significaciones cuya lógica combinatoria es la que otorga sentidos al discurso. Cabría aquí retomar la reflexión del mismo autor (1968b:24$25)$, referida al paralelo existente entre el mito y la obra musical: ambos deben sus estructuras a partituras subyacentes, ambos son lenguajes que trascienden el plano del lenguaje articulado y ambos superan la antinomia entre la historicidad que les es propia y la atemporalidad de sus estructuras, conjugando la diacronía con la sincronía ${ }^{4}$. La óptica estructuralista demostró que el mensaje mítico admitía lecturas insospechadas; se podrá tal vez no estar de acuerdo con lo que el mismo Lévi-Strauss leyó en tal o cual mito, pero creo que demostró que una lectura alterna es posible. Queda claro que el mito es un mensaje que admite múltiples lecturas sin que necesariamente una de ellas sea la única posible. Y en el caso que estoy exponiendo, la pobreza compartida por todos los pueblos indígenas opera como una estructura subyacente, que condiciona la reiterada aparición de ciertos mitemas similares, un mensaje compartido por sociedades sin relaciones históricas o culturales posibles. Así, como veremos, encontramos "mitos de privación" desde Tierra del Fuego hasta las márgenes meridionales del Rio Bravo5.

Ahora bien, los mitos que formaban y forman parte de los sistemas religiosos de muchos de los pueblos de Oaxaca, de México y de América Latina, fueron con frecuencia suplantados por los mitos de la religión católica impuesta por los colonizadores; razón por la cual muchos de ellos se han perdido o dejaron de ser considerados como relatos verídicos. Este último proceso es el que se denomina "desacralización del mito", ya que éste deja de ser creído cierto y pasa a ser considerado como un cuento que relatan los abuelos. Sin embargo, estos "relatos de los abuelos" constituyen uno de los testimonios de los ricos y complejos sistemas de pensamiento locales desarrollados durante milenios. Pero, por otra parte y a pesar de la pérdida de su nor- 
matividad y vivencia sagrada, los mitos ofrecen a los miembros de las culturas nativas datos fundamentales referidos a sus propios principios y ordenamientos lógicos y simbólicos. Lo que me importa destacar es que en la narración mítica, al igual que en el acto de escuchar música, la participación estética del escucha no está necesariamente guiada por la comprensión sino básicamente por el acto de compartir una emoción. Oír un relato mítico, aun habiendo perdido la capacidad de creer en él, puede ser equivalente al acto de escuchar la vieja música de la cultura en la que se conjugan la apelación emotiva al pasado y sus enseñanzas para el presente. Así, aunque un escucha nativo pueda conocer los orígenes "históricos" seculares de los blancos, o tener una clara conciencia política de las contradicciones étnicas del presente, podrá sentirse aún conmovido o motivado por las narraciones que refieren al origen de la presencia de los irreductibles "otros".

\section{La Invención del Otro por los "Bárbaros"}

Oaxaca en particular y México en general son ámbitos en los cuales las deidades locales se conjugan con otras reformuladas para cumplir con similares propósitos que las preexistentes; se les cambia de nombre para poder rendirles culto sin ser reprimidos o se adicionan deidades importadas de acuerdo con la tradicional perspectiva incluyente del politeísmo. Los códigos simbólicos propios de cada cultura han "leído y traducido" los símbolos del cristianismo de acuerdo con su propia lógica y construido entonces un marco referencial para su orden social, que logra excluir la eventual contradicción entre lo propio y lo apropiado (M. Bartolomé, 2008a). Algo similar ocurre cuando las ontologías locales intentan explicar la existencia de los diferentes, de los "blancos", siguiendo los parámetros de sus propias lógicas simbólicas. Pero si los mitos tratan de explicar el origen de la presencia de esa "otredad" que se impone de manera avasallante, también tratan de explicar la consecuencia o consecuencias de dicha presencia, que históricamente se ha constituido como sistemas coloniales y neocoloniales opresivos, orientados a despojar y explotar a las poblaciones nativas. Precisamente, a estos últimos relatos los califico como mitología de privación (M. Bartolomé y A. Barabas, 1996; 
M. Bartolomé 2008a), entendida como una variedad de las mitologías de contacto. Esto es, una reflexión simbólica que surge para explicar el despojo de los indígenas y la apropiación diferencial de bienes de los no indígenas. A través de este tipo de relatos las víctimas del colonialismo tratan de definir el origen de la culpa que dio lugar a la situación actual, explicarse el porqué del castigo histórico que han recibido, porque aún más intolerable que los padecimientos sufridos sería su falta de sentido. Esta situación crítica que los pueblos indígenas han vivido desde la época colonial puede caracterizarse como de privación múltiplé, ya que es económica, política, social, religiosa y psicológica. Su vivencia prolongada genera ideologías de precariedad existencial e inferioridad social, que en sus expresiones más anómicas conducen a la orfandad de significados del mundo. La mitología de privación es entonces una expresión contemporánea de la privación múltiple, internalizada por la sociedad y reproducida en el sistema simbólico, que exhibe las relaciones interétnicas como relaciones desiguales entre los poseedores de los bienes y los desposeídos, entre los privilegiados y los que sufren. Esta mitología explica simbólicamente las causas de la pobreza, otorgando de esta forma sentidos posibles a los padecimientos (M. Bartolomé, 1976, p. 545).

Comenzando por algunos de los pueblos de Oaxaca, los llamados Chontales (Lajpima; los "parientes") de la Sierra Sur, se registra un relato del nacimiento de Cristo en el que la Virgen pedía al Santo Patrono de los chontales que se revolcara en la placenta. Debido a que éste se negó su pueblo fue condenado a trabajar duramente y a vivir en la pobreza. En cambio el Santo Patrono de "los de afuera" (los extranjeros, no parientes) accedió a revolcarse y como recompensa la deidad les otorgó más bienes y prosperidad que posibilitan una vida más fácil (Bartolomé y Barabas, 1996, p. 219). Los Santos Patronos son los emblemas identitarios de los pueblos y comunidades indígenas de Oaxaca, sus acciones repercuten sobre la colectividad de los creyentes, aunque éstos no tengan responsabilidad en los hechos que se narran. Así lo ejemplifican otros tipos de relatos que dan cuenta del papel fundacional de los Santos, cuyas presencias y deseos suelen dar origen a los pueblos y localidades. Por lo tanto, no es nada aventurado destacar que este relato reproduce las lógicas intervinientes en las representa- 
ciones sociales que aluden al papel fundamental de los Santos, que forman parte de las cosmologías locales aunque sus figuras sean de origen católico. Pero el culto que se les rinde y la vivencia social de los mismos remiten a principios y códigos nativos, aunque esos códigos expresan ahora la vivencia de una derrota, ya que justifica la privación del pueblo chontal y la abundancia adjudicada a los "de afuera".

A su vez, entre los Mixes (Ayuuk) existe un motivo en el extenso ciclo de Cong Hoy, héroe cultural mesiánico que sigue siendo objeto de culto y referente ideológico, en el cual el héroe entra en conflicto con su hermana Santa Dios, quien lo abandona llevándose el maíz, el frijol y el chile hacia la costa, dejándolo en la mayor pobreza rodeado por sus hijos hambrientos. Aunque después Cong Hoy obtiene el perdón de su cruel hermana, logrando que vuelvan a darse las cosechas, queda el precedente de que todos los bienes pueden desaparecer súbitamente ${ }^{7}$. En este caso, la causa de la pobreza de los indígenas es el conflicto entre las entidades míticas, pero en esa disputa interviene la deidad de los no indios que es hermana pero rival del héroe Ayuuk. De esta manera, y tal como ocurre en diferentes sociedades nativas contemporáneas, la mitología otorga una explicación a la privación y el sufrimiento actual, proporcionando un marco simbólico para la comprensión del conflicto interétnico. A este código mítico, quizás derrotista, que expresa una vivencia de la privación y de la dominación simbólicamente legitimada, se contraponen las rebeliones mesiánicas del pasado y las movilizaciones etnopolíticas actuales, que alientan la esperanza y la acción orientadas hacia el rechazo de los colonizadores y la reapropiación de un mundo del que anhelan volver a ser destinatarios.

Para los Zoques de las selvas de Chimalapas, en el Istmo oaxaqueño, la hegemonía de Zapotecos y mestizos se debe a una competencia entre los Santos Patrones Vicente Ferrer de Juchitán (zapotecos), Santiago de Niltepec (mestizos) y San Miguel de Chimalapas Zoques). Al producirse una batalla entre Santos, San Miguel (el Santo Zoque) voló hasta el campo de batalla, exterminó a los enemigos y fue a presentarse ante Dios acompañado del Santo de los Zapotecos de Juchitán y del de los mestizos de Niltepec. Dios le ofreció de recompensa a San Miguel ganado, oro y un reloj, pero éste no aceptó 
y entonces los bienes fueron entregados a los Santos de zapotecos y mestizos. Cuando San Miguel se arrepintió y protestó sólo le fue concedida una tralladora (aparejo) para hacer mecates, condenándolo a la pobreza junto con su pueblo (Trejo, 2005, p. 198). La región multiétnica del Istmo de Tehuantepec, fue conquistada hacia el siglo XV por zapotecos provenientes de los Valles Centrales; desde esa época se transformaron en el grupo señorial rector de las otras colectividades étnicas locales (Zoques, Mixes de la región baja, Huaves y Chontales de la costa). Dicha situación ha llegado hasta el presente, cuando los zapotecos binizá constituyen el grupo económicamente dominante e ideológicamente rector de la región, desempeñando el papel que en otros ámbitos ocupan los mestizos. El relato justifica este jerárquico sistema interétnico nativo. La evangelización implicó la creación de un nuevo discurso; los viejos sistemas simbólicos se vieron alterados por la continua penetración de los nuevos significantes y significados, símbolos y sentidos, que paulatinamente ingresaban en su ámbito. Su impacto no podía ser ignorado ni eludido, y con el correr de los años sus mismas elaboraciones simbólicas se vieron sutil o intensamente permeadas por significaciones y representaciones que no estaban originariamente comprendidas en los códigos de los textos culturales preexistentes (M. Bartolomé, 1988).

Los sistemas cosmológicos desarrollan sus propias estructuras de cognición y de sentido que los van construyendo y reconstruyendo a lo largo del tiempo, demostrando su historicidad y dinamismo. Así, por ejemplo, la utilización de psicotrópicos o el viaje onírico por parte de los especialistas chamánicos de los Chatinos (Cha'cñá), van reestructurando gradualmente las cosmologías de acuerdo a las enseñanzas recibidas en las comunicaciones con lo extrahumano. Antes las deidades debían pronosticar el probable resultado de las cosechas, ahora la interrogación de los ne ho'o (Hombre Santos) incluye las consecuencias de la reciente e incierta migración a los Estados Unidos (M. Bartolomé y A. Barabas, 1982). Los cambios en la realidad social de cada grupo requieren de una ampliada explicación cosmológica, que implica la construcción de nuevos discursos que proporcionen sentidos para entender los cambios en el mundo. 
Ejemplo de lo anterior lo constituyen los Cuicatecos, quienes son una sociedad donde se registra una alta migración, una cultura de migrantes cuyos referentes normativos y axiológicos no son equiparables a los de otro grupo migratorio, sino que se vinculan con una específica realidad étnica. El territorio considerado propio no es sólo la aldea de nacimiento, sino un ámbito territorial montañoso presidido por las potencias opuestas y complementarias del Cerro Cheve y del Cerro del Rayo. En el primero se encuentra la Cueva Cheve, lo que algunos traducen como Cueva del Diablo, donde se realizan rituales cuya naturaleza se considera oscura ya que se los supone dedicados a realizar maleficios a los enemigos, que es utilizada por los brujos para "dañar" a las personas a través de invocaciones al aspecto maligno de las deidades locales, y establecer compromisos espurios en los que el individuo debe entregar el alma a cambio de bienes y dinero ${ }^{8}$. Su opuesta es la Cueva del Rayo, a la que todos insisten en considerar como un templo sagrado y benéfico, donde mora el Señor del Rayo u Hombre Rayo (Sa'anDavi) y a la que se acudía hasta hace unos 60 años para solicitar lluvias. Este Señor del Rayo es la figura cosmológica que ocupa un papel fundamental dentro de la cosmología Cuicateca (I. Schouten, 1991). Las peregrinaciones a la cueva eran públicas e incluían las bandas de los pueblos, pero se dejaron de practicar por razones que nadie sabe explicar muy bien, aunque muchos las atribuyen a la influencia católica. Ahora, a pesar de las sequías, que incrementan el número de migrantes, al parecer no se atreven a reanudar el antiguo culto, aunque atribuyen a su ausencia la precariedad de las actuales condiciones de vida. Así lo expone el siguiente relato ya que intenta justificar las penurias del presente, como consecuencia de una trasgresión cosmológica cometida por toda la sociedad en un tiempo remoto (recogido en Santos Reyes Pápalo, 2005):

[...] El Rayo estaba aquí (en el pueblo) y su mujer estaba allá (hacia la fértil región chinanteca) por donde llueve todavía, pero parece ser que ya no le hacían caso. Ya no le llevaban ofrendas a la Cueva del Rayo (ya vakudave), porque antes cada vez que le llevaban ofrendas llovía. Pero cuando le dejaron de llevar ofrendas Rayo se molestó y se fue a donde está su mujer, es desde entonces que empezó a escasear el agua. Antes la temporada de aguas 
era igual para nosotros que para los chinantecos, pero el Señor Rayo se molestó y se fue. Ahora en la cueva sólo quedan vestigios de platos y de ollas, porque la gente ya no quiere ir a dejarle ofrendas. Fue como hace 70 años que los curanderos (so'ocueae) del pueblo dejaron de hacer ofrendas en la cueva $[\ldots]$

En la cultura Cuicateca, como en muchas otras de Oaxaca, existe la ideología de que antes todo era mejor, que todas las cosas funcionaban de manera coherente y armónica, que había bastante alimento y buenas cosechas, y los habitantes no tenían necesidad de migrar para conseguir comida y edificar sus casas. Pero desde que abandonaron sus tradiciones, o algunas de las tradiciones consideradas muy significativas, fueron castigados por los Dueños o Señores de la Naturaleza de los que depende la reproducción de la vida. Es por ello que se ven obligados a emigrar hacia otros lugares, castigados con la privación de la lluvia y de los productos tradicionales; víctimas de sus propios anhelos de bienes y dinero. Es decir, que se asumen como responsables de la situación actual, que en realidad es producto del accionar del neocolonialismo estatal y eclesiástico.

\section{Una Presencia Mexicana}

En todo México se puede advertir que cuando las sociedades indígenas piensan en su inserción dentro de los actuales sistemas interétnicos, suelen registrarse dos grandes tipos de procesos reflexivos. Uno es el que está presente en las movilizaciones etnopolíticas y que maneja un discurso explícito, propio o apropiado, que tiende a analizar, con menor o mayor claridad, las causas y características de sus posiciones sociales subordinadas. Se trata de una expresión discursiva que recurre a argumentos comprensibles para la lógica estatal (más o menos occidental) y que plantea sus demandas dentro de esa misma lógica, tales como dotaciones agrarias, derechos autonómicos, educación bilingüe, etc. Pero por otro lado se registra un discurso estructurado dentro de los parámetros del sistema cultural propio, que intenta comprender la precariedad del presente de acuerdo al marco referencial que le ofrecen sus propios códigos simbólicos. El discurso 
de tipo occidental es bastante conocido, puesto que está presente en una multitud de documentos y en las demandas políticas de organizaciones o individuos. Mucho menos conocido es el discurso referencial mítico que trata de entender la conflictiva realidad en la que están insertos, de acuerdo con los recursos simbólicos derivados de sus aproximaciones cognitivas al pasado y al presente. La sola existencia de estos mitos interétnicos revela la plasticidad del discurso mítico, capaz de proyectarse sobre nuevas realidades y convertirlas en símbolos compatibles con la propia experiencia simbólica. Veamos algunos ejemplos provenientes de distintos ámbitos culturales y geográficos de México que permiten dar cuenta de la intensidad de la presencia de esta recurrente interpretación mítica.

Es interesante destacar que con alguna frecuencia se señala la existencia de un origen compartido por indígenas y blancos, tal como lo plantean los O'odam de Sonora, para los cuales indígenas y mestizos formaban parte de una categoría indiferenciada antes de que ocurrieran sucesos del tiempo originario que marcaron la separación. El mito relata que un águila raptaba a la gente y la llevaba a su cueva amontonándola en una gran pila, el miedo hizo que los O'odam pidieran a su Hermano Mayor, el héroe I'itoi, que los ayudara y este transformado en mosca se introdujo en la cueva, recuperó su forma y derrotó al águila. Después fue sacando a la gente del montón y los primeros que salieron fueron los O'odam y los apaches y finalmente salieron las persona de abajo, que habían quedado blancas y frías, quienes fueron los antepasados de los chúchikas (blancos). Pero para compensarlos I'itoi les entregó las plumas de águila que dieron origen a las lapiceras, la escritura y el consecuente dominio cultural de los blancos (Aguilar Zeleny, 2005). Como ya lo he señalado, la mitología de privación se refiere a una apropiación, pérdida o posesión diferencial de los bienes, lo que da lugar a la supremacía de un grupo sobre otro. En este caso, la compensación para los pálidos blancos representó la fuente potencial de su dominio; incluso en algunas versiones del mismo mito el águila les entrega directamente bolígrafos, actualizando así la arcaica noción de pluma de escribir. En otros casos el castigo o la pérdida de los indígenas proviene de una prueba que no lograron superar y en 
la que fueron superados por "los otros". Un ejemplo de pérdida por incumplimiento con lo sagrado lo proporciona la mitología de los Teenek de la huasteca, entre quienes se registró la siguiente narración: los abuelos de los indígenas y de los mestizos encontraron tirado en un camino a un anciano desnudo, que al parecer era Jesucristo en completo estado de ebriedad. Los Teenek se rieron y se alejaron, pero los mestizos lo recogieron y lo vistieron. Al advertir Dios el hecho, condenó a los Teenek a ser pobres y mal vestidos, en tanto que favoreció a los mestizos con buenas ropas y riquezas (Valle e. al., 2005).

\section{La Mitología de Privación en América Latina}

La presencia de estos mitos de privación no constituye un fenómeno exclusivamente mexicano, ya que ha sido también registrado en muchos de los pueblos nativos de América del Sur (M. Bartolomé, 1976), aunque la riqueza de su análisis, que varía de acuerdo a los distintos contextos interétnicos, está lejos de ser agotada. Toda sociedad sometida a un proceso dinámico se ve en la necesidad de modificar su ideología. Por lo tanto, creo que puede considerarse común a todos los pueblos indígenas que soportan similares formas de opresión y eventual redefinición existencial. Como resulta frecuente la antropología brasileña, que posee una larga tradición en el estudio de la mitología, fue una de las primeras en registrar y analizar la importancia de este tipo de reflexión simbólica. Ya desde 1950 Darcy Ribeiro había advertido que los mitos de origen que los cronistas recogieran entre los señoriales Kadiweu, señalaban que ellos estaban destinados a dominar a los otros pueblos del Chaco. Este destino había sido establecido por el héroe cultural Caracara de acuerdo a su distribución de la riqueza originaria: los Kadiweu llegaron tarde al reparto y no les tocaron tierras, pero si las armas para despojar a los otros de las suyas. Los años de dominación blanca pesaron sobre esta concepción hasta que en una versión recogida en 1947, el sentido de dominio de los Kadiweu fue transformado en humildad y la alegoría sobre la distribución de la riqueza, sólo pretendía explicar su condición de pobres cazadores nómadas. Según Ribeiro estas formas simbólicas reflejan el drama de la destribalización y todos los desajustes que acarrea la sumisión al 
blanco dominador (1950, p. 32). Para los Kaapor del Brasil, Mairá - su principal personaje mítico - era considerado como un indio Kaapor por las narraciones tradicionales. En la actualidad hay dudas sobre el color de la piel de Mairá, quien, en oportunidades, aparece totalmente occidentalizado. Incluso hay relatos que informan que Mairá les enseñó a los blancos a hacer armas de fuego, herramientas, etc. y a los indios sólo arcos y flechas (Darcy Ribero, 1970). Como vemos, en el primer caso la mitología de privación se registra como una modificación del mito de los orígenes y en el segundo caso como un nuevo mitema o episodio del ciclo del héroe cultural, demostrando en ambos casos su clara conexión con la mitología tradicional.

Otro distinguido etnógrafo brasileño Julio Melatti (1972, p. 11) pudo vincular el mesianismo de los Krahócon el mito que relata el origen de los blancos. Se trata de Auké, un héroe civilizador, que otorga bienes a los hombres, pero que provoca el rechazo temeroso de éstos que lo alejan de la aldea, razón por la cual Auké da origen a los blancos, exteriores a la aldea pero poseedores de los bienes. Este autor muestra cómo todo el grupo indígena intenta transformar sus relaciones con los blancos mediante un movimiento socio-religioso inspirado en este mito de origen de los "civilizados", cuyos bienes anhelan poseer. Es decir, que la tradición de la mitología heroica local sirve para tratar de explicar tanto la situación actual como las posibilidades de transformarla. Melatti profundizó en el estudio del tema analizando el surgimiento de los blancos dentro de un ciclo mítico de los indígenas amazónicos Marubo (J. Melatti, 1985). Así advirtió que esta aparición fue desarrollada dentro del mito de Shoma Wetsa, que incluye ambiguos episodios de exo y endocanibalismo, del que primero eran víctima los Marubo y después los "civilizados". Uno de sus episodios incluye diferentes destinos para las almas de la entidad después de muerta. De éstas, la del lado izquierdo se transforma en "los civilizados", para los cuales Shoma Wetsa fabrica "todo", rifles, haciendas, camiones, aviones, etc 9 . No cabe entonces duda de que la aparición de los "civilizados" (término local para blancos y mestizos), se formula dentro de la lógica simbólica preexistente.

No intentaré aquí agotar los ejemplos sobre el tema, pero dentro de la casuística brasileña vale la pena recobrar la pequeña antología 
sobre "A chegada dos brancos", publicada por el Instituto Socioambiental del Brasil en el 2000, con un comentario del antropólogo Eduardo Viveiros de Castro. Los textos relatan el origen de los blancos según los Krenak, los Yanomami, los Zo'é, los Mawé, los Baré, los Sateré-Mawé, los Desana, los Kuikuru y los Wapishana, dando cuenta de la difusión panamazónica de este tipo de mitemas. Sin embargo el análisis de Viveiros está orientado por una óptica estructuralisla que le impide aproximarse al drama social que expresa la narrativa. Su punto de partida es el ensayo del pionero estructuralista brasileño Roberto da Matta (1979), quien advirtió en el mito de origen de los blancos entre los Timbira, el mito de Auké, una inversión del mito del origen del fuego, lo que lo ubicaba dentro de la mitología tradicional ${ }^{10}$. Así, Viveiros reflexiona sobre la lógica mítica que presupone la existencia de los blancos en el tiempo de los orígenes, atribuyéndola a que una de las características de la estructura constitutiva de esa construcción artificial que llama el "pensamiento indígena" (¿̇?), es la operación dicotómica que le impide pensar un término sin concebir de manera simultánea su opuesto; así el surgimiento de los indios supone el surgimiento complementario de los blancos. De la misma manera interpreta los mitos que llama de la "vida breve", que relatan la pérdida de la inmortalidad o de capacidades humanas resultante de una mala elección de los antepasados dando lugar a una privación actual, como expresión de un pensamiento dual que requiere que para que haya algo debe existir lo contrario, es decir que para haber muerte tiene que haber los que no mueren, y éstos serían los blancos. En ese diálogo de símbolos, atribuidos a un indemostrable "pensamiento amerindio" que hace recordar a la arcaica "mentalidad prelógica" de Lévi-Bruhl (1974) o al "pensamiento salvaje" de su referente Lévi-Strauss (1964); la sociedad concreta desaparece y es reemplazada por símbolos producidos por características inherentes a un tipo de pensamiento ahistórico y al parecer incapaz de reflexionar sobre los cambios contextuales por los que atraviesa la sociedad ${ }^{11}$.

En muchos casos, la mitología de privación propone una inversión simbólica de los procesos históric

os, haciendo a los indígenas responsables de su actual pobreza como 
resultado del proceso de aculturación del cual se sienten culpables, aunque les fuera impuesto desde el exterior. Al igual que en el caso oaxaqueño de los Cuicatecos, los Tikuna del Brasil creen ahora que sus padecimientos se deben al incumplimiento colectivo de sus normas culturales, en realidad producto de la dominación de misioneros y hacendados. De esta manera se internaliza una ideología de subordinación existencial, motivada por actos de los que las propias víctimas del despojo se consideran protagonistas y culpables. Se exime a los blancos de sus responsabilidades y se propone una culpa original de la cual resulta la precariedad del presente, así lo expone F. Ullán de la Rosa (2006, p. 192):

[...] Cuenta el génesis Ticuna que los dioses gemelos Yoí e Ipi crearon a los magüta (término que utilizan para denominarse a sí mismos en su lengua), inmortales, sabios y poderosos y que así vivieron con ellos durante mucho tiempo en una montaña mágica, el Taiwegüne, especie de Jardín del Edén. Hasta que un día una parte de los magüta desobedeció las reglas establecidas por Yoí; en particular dejaron de observar los ritos de iniciación femenina (worekü) y de vivir en malocas, elementos fundamentales en la cultura Ticuna. La desobediencia provocó la ira de/del Dios, que los expulsó de Taiwegüne, los condenó a la mortalidad y a perder sus poderes y su sabiduría. Como consecuencia de este "pecado original» nacieron los actuales Ticuna, seres débiles, inferiores que, debido a esa debilidad, pronto cayeron bajo el poder de los blancos $[\ldots]$.

Diferente es la empresa que desarrollara Jonathan Hill (1988), al advertir la difusión de esos motivos míticos tanto en las tierras altas como en las bajas de Sudamérica. Dicho autor propone precisamente que la existencia de esta clase de narrativa supone la conjunción de una conciencia mítica con una conciencia histórica, que no son excluyentes. A su vez, el brasileño Carlos Fausto (2002) analizó la mitología sobre el origen de los blancos entre los Parakaná, un grupo Tupí del Brasil, destacando que la experiencia del contacto se multiplica en una gran cantidad de mitemas sobre este hecho histórico. Propone así la existencia de un "alargamiento de los mitos" lo que produciría una “condensación mítica, que supone una chamanización del discurso 
al intervenir entidades extrahumanas. Destaca que los Parakaná no distinguen entre historia y mito, y establece una diferenciación entre ambos basada en la capacidad de acción de los protagonistas, que en el primer caso serían humanos y en el segundo, humanos y extrahumanos. Concluye entonces Fausto señalando que la llamada capacidad de acción histórica para los indígenas (historical agency) sería la acción chamánica sobre el mundo. En este mismo sentido hace mucho tiempo que Georges Balandier (1975, p. 211 ) había apuntado la relación formal existente entre el mito y la historia, en la medida en que ambos son relatos. Incluso señala que toda narración histórica combina en su discurso algo de mythos y de logos, no siendo infrecuente que el primero tienda a predominar. Aceptando entonces la existencia de una "agencia simbólica", no es nada extraño que la mitología de contacto conjugue el mito con la historia, dentro de una totalidad simbólica que no necesita diferenciaciones internas. De allí que estos relatos resultan fundamentales para comprender los contextos y procesos históricos por los que ha atravesado cada cultura. Esta narrativa presenta entonces a los indígenas como protagonistas reflexivos de los procesos históricos, pero que se expresan en sus propios términos y símbolos.

En otros ámbitos de las tierras bajas sudamericanas también se registran numerosos ejemplos de la mitología de privación. Para los Campa del Perú, los viracocha (blancos) estaban dentro de una laguna de la que fueron sacados por el error de un indígena. Al salir mataron a todos los Campa menos a un chamán. Mediante el auxilio de un animal mítico que le proporciona la "yerba mágica" (coca), el chamán puede matar a todos los blancos (este sería un motivo del tipo "la vida breve" de Eduardo Viveiros de Castro). Sólo un hombre se salva y huye al río Ucayali donde, desde entonces, hay muchos blancos. También existe un mito Campa según el cual las hachas, los machetes y los instrumentos metálicos en general, son enviados por el Dios usando de intermediarios a los blancos y a los indígenas andinos (S. Varese, 1968). Los Piaroa de la amazonia venezolana, tratan de adaptarse a la nueva economía dominada por el monetarismo explicando mitológicamente la conducta de los blancos. Para ellos el dinero es una manifestación concreta de poderes mágicos. Fue el héroe cultural de los Piaroa, Wa- 
hari, quien decidió que los blancos debían ser ricos y los Piaroa pobres, puesto que distribuyó los objetos de metal entre los blancos dejando a los indígenas solamente los recursos de la selva (J. Monod, 1970).

\section{La Reivindicación Simbólica}

Esta mitología del origen de la privación contemporánea suele estar acompañada por una reflexión de la misma naturaleza que propone la superioridad moral de los indígenas ante los no-indígenas, identificados con las fuerzas del mal o con las impurezas que introducen el caos en la vida social. Se trata de una recuperación simbólica de la propia autoestima a pesar de las condiciones objetivas que imponen la subordinación social. En muchos de los grupos indígenas de Oaxaca (zapotecos, mixtecos, chatinos, chinantecos, zoques, etc.) hemos recogido la noción de la existencia de un ser poderoso, en algunos casos identificado con el Señor del Cerro, elegantemente vestido como occidental, que ofrece riquezas a cambio del alma de los viajeros con los que se encuentra en los caminos. Dentro de las cosmologías locales el Señor o Dueño del Cerro es una entidad extrahumana que controla el acceso a las riquezas contenidas dentro de las montañas, de acuerdo con la tradición mesoamericana de la Montaña Sagrada, entendida también como "[...] cerro de bastimentos". Esto designa al lugar donde se concentran los bienes ya sea en forma de maíz, animales de caza, oro, joyas y, ya en la actualidad, electrodomésticos y automóviles. Cuando esta entidad éticamente ambigua ofrece ese contrato fáustico a los viajeros, bienes a cambio de su espíritu, los individuos se enriquecen pero sus vecinos reconocen que este acceso a una desmesurada posesión de bienes significa que el destino del propietario está sellado, tal como lo demuestra la rapidez con que su cuerpo se descompone después de la muerte. Este "catrín" (elegante occidental) o "sombrerudo" (charro) que encarna a las tentaciones del Demonio, es siempre blanco y las riquezas que ofrece son por lo común enumeradas como productos occidentales tales como automóviles, camiones, armas de fuego, electrodomésticos, etc. El que quiera seguir por un camino recto, respetando la vida comunitaria y su propia cultura, no debe entonces tratar con el Diablo. El Diablo es blanco y, 
al parecer, capitalista.

De la misma manera para los Rarámurí (llamados tarahumaras), los chabochis (barbados, extranjeros) son hijos del Diablo, en tanto que ellos son hijos de Dios; sin embargo Dios es el hermano menor (a veces mayor) del Diablo, por lo que chabochis y Rarámuris son en realidad primos (Porras, 2005). Pero al ser los dos grupos hijos de hermanos del mismo sexo, es decir primos paralelos, se supondría que las alianzas matrimoniales no estarían bien vistas ya que adquirirían un carácter incestuoso. Esto justifica la endogamia grupal y la necesidad, al menos teórica, de evitar las uniones interétnicas para mantener la ancestralidad e identidad diferencial de los Rarámuris. Entre los Teenek, conocidos como huastecos, a los mestizos se les atribuyen algunas de las características del Diablo, hasta el punto que se utiliza el mismo término, teeneklab, para designar a ambos (Valle, et al., 2005). La identificación del "otro" con lo maligno, con lo demoníaco, corresponde a una irrupción de la cosmología cristiana en el mundo indígena, ya que asume el dualismo ético de las deidades en oposición del monismo tradicional, en el que las deidades no son ni buenas ni malas en sí mismas, puesto que sus conductas dependen de las relaciones de interacción que se tengan con ellas. Los Guarijíos de Sonora también se consideran hijos de Dios, confrontados con los yoris, mestizos o blancos, hijos del Diablo, incapaces de lograr una adecuada comunicación con las deidades debido a que pretenden hacer ceremonias utilizando la lengua castellana, en lugar del idioma Guarijío, siendo a la vez identificados con los mismos principios clasificatorios que sirven para designar a todo lo vinculado con el inframundo (Conde, 2005). Para los mayas Chamulas de Chiapas, las diferencias entre los humanos se originaron después del diluvio que acabó con la primera tierra, a la inundación sobrevivió una mujer con un perro al que obligó a tener relaciones con ella y de esa unión surgió el primer ladino, el primer mestizo. En cambio los Chamulas fueron creados por el Padre Sol, quien les permitió alimentarse de su propio cuerpo (Gossen, 1979, p. 385). Al parecer queda bastante claro que están clasificando míticamente a los mestizos como "impuros hijos de perra".

Las siguientes informaciones y reflexiones quizás no corresponden al título de estas líneas, aunque podrían (y deberían) dar lugar 
a un ensayo específico, por lo que me limitaré sólo a destacar su presencia a través de un par de ejemplos. En varios grupos, en especial en aquellos que no han padecido prolongadas situaciones coloniales, se suelen encontrar narraciones que afirman la propia etnicidad en contra de la presencia y cultura de los blancos o criollos. En algunos casos, como hemos visto entre los mayas Chamulas y para los Teenek, a pesar del colonialismo se mantiene una afirmación positiva. Algo similar ocurre respecto a la superioridad moral que manifiestan otros grupos mexicanos. Pero esto se hace particularmente visible en las sociedades nativas con las que los estados nacionales han establecido relaciones relativamente recientes. Así, por ejemplo, los Yanomami del Brasil y Venezuela, que han sido contactados en la segunda mitad del siglo XX, cuyo "salvajismo" y "violencia innata" han sido objeto de grotescas especulaciones por partes de antropólogos partidarios de la sociobiología, como el tristemente célebre Napoleón Chagnon (1968), responden al prejuicio étnico con su propia axiología que inferioriza a los inferiorizadores. Gracias a la labor del antropólogo Bruce Albert (1999) podemos contar con los testimonios de sus protagonistas. El siguiente texto es un fragmento de una narración más extensa recogida por dicho colega (mi traducción):

[...] Los blancos son ingeniosos, tienen muchas máquinas y mercaderías, pero no tienen ninguna sabiduría. No piensan más en lo que eran sus ancestros cuando fueron creados. En los primeros tiempos ellos eran como nosotros, pero olvidaron todas sus antiguas palabras. En los primeros tiempos los blancos vivían como nosotros en la selva y sus ancestros eran poco numerosos. Oamama les transmitió también a ellos sus palabras, pero no escucharon. Pensaron que eran mentiras y se pusieron a buscar minerales y petróleo por todas partes, todas esas cosas peligrosas que Oamama quiso ocultar bajo la tierra y bajo las aguas porque su calor es peligroso. Pero los blancos las encontraron y pensaron hacer con ellas herramientas, máquinas, automóviles y aviones. Entonces se tornaron eufóricos y se dijeron: inosotros somos los únicos en ser tan ingeniosos, sólo nosotros sabemos fabricar las mercaderías y las máquinas!. Fue en ese momento que ellos perdieron realmente toda su sabiduría. Primero destruyeron su propia tierra antes de 
ir a trabajar en la de los otros para aumentar mercadería sin parar $[\ldots]$

En otras ocasiones, la sociedad nativa afirma su superioridad en términos de su axiología, aun reconociendo el poder fáctico que obra en manos de los blancos. Un buen ejemplo se encuentra en la mitología antropogónica de los Desana, habitantes de una de las afluentes amazónicas del Rio Negro, quienes incluyen en sus mitos a los blancos estableciendo a nivel cosmológico las características y comportamientos destructivos de estos "hermanos menores", ya que fueron estipulados por el héroe cultural desde el comienzo de los tiempos. No me puedo resistir entonces, a reproducir mi traducción de un fragmento del extenso relato recogido y publicado por una colega francesa (D. Buchillet, 1993, p. 19-21):

[...] Para nosotros, los Imiko-masä, "La Gente Del Universo", los Desana, La humanidad entera, tanto los indios como los blancos, tienen el mismo origen. Cuando Pamiri-gasiru (La Canoa de las Transformaciones) llegó al Río Uaupés, los ancestros de la humanidad ya tenían forma humana y comenzaron a salir por el agujero de la Canoa. Los ancestros de aquellos que serían los blancos también estaban en la Canoa. Ellos fueron los últimos en salir. Nuestro héroe fundador Yebá-goami los mando hacia el sur, diciéndoles que allá ellos podrían hacer la guerra, ellos podrían robar y atacar a las personas para sobrevivir. Para nosotros, que somos los hermanos mayores de los blancos, el Gran Ancestro nos dio la orden de quedarnos tranquilos, viviendo unidos y de manera pacífica. Pero a los hombres blancos les dio la orden de ganarse la vida por la violencia, haciendo la guerra, matando. Así, cuando los primeros blancos llegaron a la región nuestros abuelos ya sabían que ellos venían para hacer la guerra...Yebagoami les dio el rifle como arma. El rifle es el poder del blanco...Con el blanco salió también el misionero de la Canoa de las Transformaciones; los dos salieron juntos... Yebá-goami le dio al misionero un libro (la Biblia) para poder vivir. Nosotros ya sabíamos que el misionero llegaría con el blanco porque así lo había dicho Yebá-goami. Por eso cuando nuestros ancestros vieron por primera vez a un misionero con su libro, ellos ya sabían que ese libro era su poder, su arma. Nosotros sabemos muy bien que 
ese libro es el arma del misionero... Nosotros vemos al blanco entrar en nuestra tierra en búsqueda de oro, de minerales. Ellos entran en nuestro territorio con violencia. Ellos quieren ser dueños de todas las cosas. Para nosotros, que somos los hermanos mayores del hombre blanco, Yebá-goami nos dio el poder de la memoria, la facultad de guardar todo en la memoria: nuestro saber no está en los libros. Pero al blanco, que fue el último en salir de la Canoa de las Transformaciones se le dio el poder de la escritura. Les habían dicho que ellos podrían obtener todo lo que necesitaban con los libros $[\ldots]$

\section{Reflexiones sobre Simbolismo y Privación}

Retomando el tema de la privación quisiera ahora detenerme brevemente en el mismo concepto de "pobreza" o privación, como lo he intentado en un ensayo anterior (M. Bartolomé, 2008b), ya que puede tener distintas acepciones de acuerdo con el tipo de contexto histórico y cultural en el que se registra. En estos casos, como en todos, la reflexión debe tener en cuenta las diferentes percepciones que son las que otorgan su especificidad a los contextos interculturales. Habría entonces que comenzar distinguiendo dos grandes modalidades diferenciales, que podríamos llamar pobreza absoluta y pobreza relativa. La primera no admite mayores reflexiones que las que ya ha hecho una ingente literatura especializada: cuando la gente no es capaz de satisfacer sus necesidades básicas de alimentación y reproducción social, la pobreza es un dato absoluto, cuyos matices pueden variar pero cuya sola existencia representa una afrenta a los derechos humanos de las poblaciones que la padecen. No cabe, en este caso, más que recordar que ningún Estado puede considerarse exitoso, ni presumir de sus logros, si parte de sus ciudadanos son víctimas de privación alimentaria o padecen enfermedades curables que, en realidad, estaría en condiciones de remediar con una mejor distribución del ingreso. La segunda, la pobreza relativa, alude a una condición en la que los parámetros de referencia varían de acuerdo con las distintas lógicas culturales. Un ejemplo podrían ofrecerlo los criterios estadísticos a los que se recurre para establecer indicadores de pobreza. Así, en México se habla de la existencia de "promiscuidad" cuando toda una familia 
vive en una misma habitación, aunque ello forme parte integrante de la experiencia vital de la gran mayoría de las poblaciones nativas, tanto por las alianzas parentales como por las relaciones de trabajoconsumo compartidas dentro del grupo doméstico ${ }^{12}$.

Por otra parte, en algunos contextos la autodefinición de pobreza no alude a la insatisfacción de necesidades básicas sino a la falta de acceso al mundo de los bienes occidentales; como manufacturas, electrodomésticos, ropas, armas y demás objetos de los que son poseedores los blancos o los mestizos. En este sentido, la noción de "pobreza" remite también a una confrontación entre sociedades, de las cuales, la no-indígena aparece como poseedora de la gran mayoría de los bienes disponibles en el mundo. Así, la pobreza indígena es vivida también como resultante de una apropiación diferencial de bienes instaurada desde el tiempo originario, porque lo que resulta cosmológicamente intolerable es la falta de significado. Y este significado lo otorga el mito, ya que tal como alguna vez lo destacara Eliade (1961:11) toda mitología constituye una ontofanía, una manifestación plenaria del ser, que revela la estructura de lo real y los múltiples modos en los cuales los seres humanos se insertan en esa realidad. La capacidad ordenadora de los mitos que, a nivel del lenguaje son palabras que circunscriben y fijan los acontecimientos, organiza la estructura de plausibilidad de la realidad. Los mitos representan así un recurso crucial ante las amenazas del caos y de la anomia -de la angustiosa pérdida de sentidos existenciales-, que se ciernen sobre todos los órdenes sociales víctimas de crisis o de relaciones de subordinación en los distintos momentos de su acontecer histórico. La pobreza material está acompañada entonces por una grave noción de privación existencial generalizada, que suele nutrir ( sin necesidad de hacerse explícita) a los movimientos etnopolíticos contestatarios, y que puede alimentar fundamentalismos étnicos en ámbitos donde la frustración social alcanza dimensiones cada vez más profundas.

Por otra parte hay otro factor fundamental que está en juego y que se refiere a las distintas lógicas económicas involucradas. Desde la colonia la presencia europea fue signada por el capitalismo y su lógica de acumulación individual de bienes. En cambio, y aunque resulte una generalización un tanto excesiva, se puede señalar que en el ámbito 
indígena prevalecía y, en muchos lugares aún prevalece, la economía social basada en la reciprocidad y la no diferenciación. Esto no se corresponde con una axiología descontextualizada, sino con una necesidad básica de las sociedades aldeanas. Aún en los sistemas tributarios mesoamericanos, andinos y del área intermedia, las comunidades que integraban los estados se regían por el principio de la reciprocidad equilibrada, que tiende a disminuir las tensiones de la vida comunitaria y aumentar su cohesión. Lo mismo ocurre en las tierras bajas tropicales y en los llanos, ya que la reciprocidad generalizada se registra tanto entre cazadores como entre horticultores tropicales. De hecho, existen mecanismos coactivos que tienden a inhibir la diferenciación social, por medio de estrategias tales como la "envidia", que despierta el pedido de la acción de los hechiceros sobre el envidiado que intenta acaparar más bienes que los demás (M. Bartolomé y A. Barabas, 1982). Aquí nos encontramos con dos sistemas valorativos muy diferentes referidos a la riqueza y la pobreza, a la posesión diferencial de bienes o a la redistribución social de los mismos: el individualismo económico frente al colectivismo comunitario. Esto no excluye que la introducción masiva de nuevos bienes por parte de los blancos cree nuevas expectativas de posesión, aparecen así nuevas necesidades sentidas como tales y la adquisición de esos bienes genera expectativas sociales ambiguas. A veces se anhela poseerlos, incluso despojando a sus poseedores, como en el caso de los saqueos o en algunos movimientos mesiánicos, en otros se pide a las propias deidades que los otorguen, como sucede en el caso de los milenarismos, o con el "culto a las mercancías" (cargo cult) protagonizado por los cazadores chaqueños (L. Bartolomé, 1972). Pero desde esas épocas sólo el ingreso a la economía mercantil o al trabajo asalariado permite adquirirlos, y la generalización de la posición social y económica subordinada hace muy difícil la empresa generando una masiva frustración colectiva.

La apropiación simbólica sigue muchos caminos. Veamos un caso: en la lógica mítica los hombres no inventan sus bienes, sino que éstos son otorgados por deidades o robados por héroes culturales. Existiendo esta forma mítica que expresa un sistema de significaciones, aparece por ejemplo el dinero como un bien que no tiene significado dentro 
del contexto previo, no es un signo. En el caso de los Wichí del chaco argentino, este bien carente de significado es incorporado a la estructura mítica al ser robado a los blancos por el héroe cultural Wekito; el robo permite relacionarlo con el contexto previo (mito heroico donde el héroe cultural roba bienes) transformándolo en un signo (M. Bartolomé, 1976). De esta manera los mitos reestructuran las antiguas construcciones de la realidad para proporcionar y definir sentidos preexistentes para los nuevos objetos del conocimiento, integrándolos a la propia noción del mundo y otorgándoles una identidad posible así como una ubicación en el espacio y el tiempo. La narrativa y su capacidad de apropiación simbólica hacen que lo no sabido, lo inexplicable en otros términos, como la presencia de los blancos y sus bienes que no figuraban en los mitos de origen, adquieran un significado y un sentido posible. El enigma de lo real se resuelve a nivel de las formas simbólicas reconstruyendo la imago mundi amenazada por la sinrazón de la falta de sentido.

Reiteraré ahora algunas reflexiones que ya me habían suscitados los mitos que recogí entre los Wichí en 1971 (M. Bartolomé, 1976). Prefiero ser redundante a tratar de decir las mismas cosas con diferentes palabras, puesto que este ensayo ratifica aquel ya lejano estudio juvenil. Un breve análisis de los textos confirma que la nueva narrativa presenta una estrecha vinculación con la mitología tradicional. Esta constituye el sustrato sobre el cual se elabora la modificación adaptativa, la que mantiene la misma estructura formal y simbólica que aparece en la tradicional. Esto es coherente con la propuesta de Barthes (1957) referida a que el mito no es un objeto, concepto o idea, sino un modo de comunicación y significación; una "forma". Y esta forma tiende a mantenerse aunque sus referencias contextuales son reemplazadas o se transforman de acuerdo con la historia del grupo que genera su reflexión. La mitología de privación demuestra que la significación mítica no está nunca concebida arbitrariamente ni signada por un solo y específico "tipo de pensamiento" o "sistema cognitivo", como lo pretende el estructuralismo ortodoxo y sus continuadores contemporáneos, sino que está siempre motivada por la historia concreta de cada cultura. La mitología de privación expresa también el carácter del 
mito, a través de la forma que éste utiliza para la apropiación de un significado y en tanto transforma sus objetos de significado en relación a la cambiante realidad histórica. En esta mitología permanece una "forma" de aproximación a la realidad; una "forma" de comunicación simbólica, de organización del mundo y de las ideas, propias de una sociedad -la indígena- y de su código simbólico.

Este tipo de reflexión mítica trata de justificar la precariedad del presente, pero básicamente de entenderlo de acuerdo con los mismos principios cosmológicos que organizaron inicialmente el mundo y la sociedad. De esta manera la contradicción interétnica quizás se legitima, pero al menos intenta ser comprendida y eventualmente subvertida, a través de los procesos de inversión simbólica que pueden reordenar los respectivos papeles de los protagonistas. El ya citado Mircea Eliade (1968:96) ha señalado con justeza la necesidad de que las situaciones angustiosas tengan algún precedente que las legalice, que respondan a algún prototipo o a algún orden, de esta forma los padecimientos pueden tener un sentido posible, aunque impliquen un castigo injusto. La falta de sentido puede ser tan angustiosa como la cercanía de la muerte, en la medida que introduce un principio de "desorden" en la vida colectiva que induce a la anomia, es decir a la pérdida de significados existenciales. Pero las perspectivas formalistas, hermenéuticas, estructuralistas, o "posestructuralistas", pocas veces se han acercado a los discursos míticos entendiéndolos como códigos dinámicos, organizadores de las ideologías sociales que ayudan a definir el ser en el mundo. Ser en el mundo no sólo de las sociedades que los elaboran, sino también del entorno que esas sociedades perciben y que adquiere el aspecto de signos comprensibles a través de la apropiación simbólica. Así, la mitología de privación contribuye a ordenar simbólicamente el mundo, ya que son relatos que pretenden dar sentido a lo que aparentemente no lo tiene, al mismo tiempo que lo vincula con la experiencia de lo extrahumano, contribuyendo a la legitimación sacralizada del universo y de todos sus sentidos posibles.

En contextos de esta naturaleza la existencia de los colonizadores es una presencia ineludible que cambia de manera radical las perspectivas existenciales comunitarias. Los indígenas se ven obliga- 
dos a practicar una especie de actualización simbólica del mundo, en concordancia con la nueva historicidad que lo invade y lo redefine. Los especialistas religiosos tienen que adecuar sus construcciones discursivas a la cambiante realidad, incluyéndola dentro de tradiciones reestructuradas que puedan dar cuenta del contraste interétnico y de la propia especificidad ante los inevitables "otros". Surge entonces una nueva perspectiva del "nosotros en situación", que induce a una necesaria reformulación de las autopercepciones de colectividades que tienen que sobrevivir frente a un grupo más poderoso. Nos encontramos ante una reformulación existencial guiada por una nueva construcción ideológica que conjuga la experiencia de la tradición con las exigencias del momento histórico que le toca vivir a la cultura ( $\mathrm{M}$. Bartolomé, 2008a). Así, la mitología del contacto y la mitología de privación forman parte del esfuerzo adaptativo de las culturas a la nueva realidad que les toca vivir, ya que es a nivel de sus construcciones simbólicas donde el hombre refleja más claramente las alternativas de su mundo vivido. Este proceso de actualización del ser social de las colectividades humanas acosadas por la desemantización, refleja también una aptitud y una actitud para asumir o reasumir la construcción o reconstrucción del universo cultural propio agredido por el colonialismo

La última observación significa que no estoy proponiendo una victimización reiterativa de las sociedades nativas; ellos han sido protagonistas de procesos históricos en los que merecen conservar su protagonismo como actores activos y no sólo como sujetos pasivos. Precisamente la dinámica mítica que demuestra la mitología de contacto, expresa que los indígenas han tenido la capacidad tanto de "inventar" a los blancos, como de "traducirlos" de acuerdo a su propia visión del mundo. Esta es, también, una forma de recuperar la iniciativa y la autonomía ideológica, de no depender de las versiones de los otros. Reconocer la privación relativa no es, como pareciera, sólo un trágico lamento histórico, es también básicamente un mensaje político, un medio para lograr fines, a través del cual se entiende el pasado y el presente; una forma de ubicarse en el espacio y en el tiempo para poder emprender un acceso propio al futuro. 


\section{Notas}

1 Antropólogo. Profesor-Investigador Emérito del Instituto Nacional de Antropología e Historia de México. Miembro del Sistema Nacional de Investigadores y de la Academia Mexicana de Ciencias. Agradezco profundamente la lectura crítica de estas páginas por parte de mi colega y amiga Alcida Rita Ramos de la Universidad de Brasilia, así como la cuidadosa corrección efectuada para su edición por el infatigable y generoso amigo Alfredo López Austin.

2 Hace ya muchos años, hacia 1971, realicé una investigación de campo sobre la mitología del Pueblo Wichí (Matacos) del Chaco argentino, que dio como resultado una publicación que estaba un poco fuera de lugar para la lógica teórica de la época. (M. Bartolomé, 1976). Gran parte de los textos recogidos relataban la relación de los indígenas con los blancos, razón por la cual mi ensayo se refirió a la que denominé Mitología del Contacto, entendiéndola como el género mítico resultante del contacto interétnico. Ya en aquella ocasión había encontrado ejemplos similares provenientes de otros pueblos indígenas, y ahora creo poder hacer extensivas mis reflexiones al caso mexicano y a Latinoamérica en general.

3 Es difícil adjudicar a otras culturas una noción de lo "sagrado" equivalente a la existente en la tradición judeo-cristiana. En esta concepción lo sagrado está vinculado a "lo santo", "lo divino" o "lo bueno". En cambio en otras tradiciones lo que con mayor propiedad podríamos llamar "extrahumano" no implica necesariamente una actitud de bondad, ya que posee una dualidad ética que responde al tipo de intercambios transaccionales que mantenga con los seres humanos (ofrendas a cambio de favores).

4 Esto contradice la misma distinción leviestraussiana entre sociedades "frías y "calientes". No existe esa historicidad cerrada, mítica, que integra el acontecimiento en las sociedades "frías" que buscan gracias a las instituciones e ideologías existentes anular de manera casi automática el efecto que los factores históricos podrían tener sobre su equilibrio y su continuidad. Esto supone que tendrían una historicidad congelada; en tanto que las otras interiorizarían resueltamente el devenir histórico para hacer de él el motor de su desarrollo. El registro etnográfico consciente de las trasfiguraciones internas de las sociedades llamadas "frías" lo contradice.

5 Las razones para esta arbitraria limitación geográfica son exclusivamente derivadas de mi especialización etnológica en América Latina y en la posibilidad de ofrecer algunos testimonios recogidos personalmente. No tengo dudas que una amplia exploración bibliográfica ofrecería un vasto registro de tipos similares de mitos, tanto en América del Norte como en el resto de las culturas del mundo que hayan padecido situaciones coloniales.

6 YoninaTalmon (1975) ha definido privación múltiple como el efecto combinado de la pobreza, la baja condición social y la ausencia de poder, que generan situaciones de inseguridad que no pueden ser superadas con los medios con que la sociedad cuenta.

7 Este relato fue recogido, aunque en forma fragmentaria, en la localidad de Tamazulapan por nuestra entonces colaboradora la lingüista mixe Margarita Cortés en abril de 1997.

8 Las investigaciones arqueológicas en la Cueva Cheve han encontrado evidencias materiales de cultos sacrificiales que se remontan al periodo Clásico. Tal vez el hallazgo más significativo haya sido una tableta de madera incrustada con turquesas que forman un complejo diseño con figuras humanas realizadas de forma semejante a las de los códices y que corresponderían el estilo posclásico conocido como 
mixteca-puebla, lo que resulta coherente con la tradición mítica de la ancestralidad nobiliaria local. Pero también se han encontrado veladoras, huesos humanos y de animales, flores secas, listas de nombres escritos en papel, muñecos con alfileres y otras evidencias de la vigencia contemporánea del culto (J. Stelle y R. Snavely, 1997).

9 J C. Melatti (1985:165) concluye señalando que "[...] llegamos a dos series de conclusiones. La primera de ellas consiste en la ya esperada constatación de que el mito de Shoma Wetsa recombina temas que se hallan presentes en otras sociedades del continente, incluso, geográficamente muy distantes de los Marubo. La segunda se refiere a cuestiones peculiares a las sociedades amazónicas próximas a los Andes Centrales, principalmente respecto a la imagen que construyen respecto a los Incas percibidos también como civilizados [...]" (en portugués en el original, mi traducción).

${ }^{10}$ Da Matta sostiene que los mitos son formas de producción y reproducción de significado en una cultura. En este caso, los Timbira consiguen explicar acontecimientos desconocidos y difíciles de expresar, como el origen del hombre blanco y su relación con las sociedades indígenas, a partir de una narración concreta y de construcción sencilla, en lo que Lévi-Strauss llama bricolage. Al fin la comunidad Krahó asume un cierto sentimiento de culpa ya que si no hubieran acabado con Auké serían como los blancos, pero cuando Auké ofrece a los indios la condición de blanco, en forma de armas de fuego, ellos las rechazan y eligen seguir con sus métodos y costumbres

11 Pero este autor señala con razón que una consecuencia de estos mitos: “... lo que dicen estas narrativas es que la relación con los blancos existió desde siempre. No hubo ni hay "contacto" que no fuese o sea una actualización -aunque desastrosa- de una realidad desarrollada en el discurso de los orígenes. Los personajes "históricos" (los que figuran en los mitos históricos) coexisten sin solución de continuidad ontológica con los personajes míticos ..."(E. Viveiros de Castro, 2000, mi traducción).

12 En lo que atañe al ingreso familiar, las estadísticas oficiales son poco creíbles cuando registran las ganancias, puesto que a ningún campesino se le ocurriría dividir el precio de venta de su cosecha por doce y señalar ese monto como su ingreso mensual: cuando es interrogado sobre su acceso al dinero, si no vendió su cosecha en ese mes o en el mes pasado, dirá que no tiene ningún ingreso.

\section{Referencias}

AGUILAR ZELENY, Alejandro. Identidades en el desierto y la sierra de Sonora, In: M. BARTOLOMÉ (Coord.). Visiones de la diversidad: relaciones interétnicas e identidades indígenas en el méxico actual, v. I, México, Instituto Nacional de Antropología e Historia, 2005.

ALBERT, Bruce. Testimonios de Davi Kopenawa Yanomami. In: NOVAES, Adauto (Org.) A Outra margem do Ocidente. São Paulo: Minc Funarte/ Companhia das Letras, Brasil, 1999.

BALANDIER, Georges. Antropo-lógicas, Barcelona, España: Ediciones Península, 1975. ( $1^{\mathrm{a}}$ ed. Francesa de 1974)

BARTHES, Roland. Le mythe aujourd'hui. Mythologies II. Paris, Editions du Seuil, 1957. 
BARTOLOMÉ, Leopoldo. Movimientos milenaristas de los aborígenes chaqueños entre 1905 y 1933. Suplemento Antropológico, Asunción, Paraguay, v. 1-2, n. 7, 1972.

BARTOLOMÉ, Miguel. La mitología en contacto entre los mataco: una respuesta simbólica al conflicto interétnico. América Indígena, México, Instituto Indigenista Interamericano (OEA), v. 36, n. 3, 1976.

. La dinámica social de los mayas de Yucatán: pasado y presente de la situación colonial. 2. ed. México, Instituto Nacional Indigenista, (Serie de Antropología Social 80), (1988) 1990.

. (Coord.). Visiones de la diversidad: relaciones interétnicas e identidades indígenas en el México actual. 4. v., México, Instituto Nacional de Antropología e Historia, 2005.

. La tierra plural: sistemas interculturales en Oaxaca, México, Instituto Nacional de Antropología e Historia, (Colección Monografías), 2008a.

. La diversidad de las diversidades: Reflexiones sobre el pluralismo cultural en América Latina. Cuadernos de Antropología Social, n. 28, Buenos Aires, Instituto de Ciencias Antropológicas - Universidad de Buenos Aires, 2008b.

BARTOLOMÉ, Miguel y Alicia Barabas. Tierra de la palabra: Historia y etnografía de los chatinos de Oaxaca INAH, Serie Antropología Social 108, México 1982. 2. ed. Instituto Nacional de Antropología e Historia Dirección de Culturas de Oaxaca. 1996.

. Etnicidad y pluralismo cultural: la dinámica étnica en Oaxaca. México, Instituto Nacional de Antropología e Historia, Colección Regiones, 1984, 2. ed. CONACULTA, 1990.

. La pluralidad en peligro. México, Instituto Nacional de Antropología e Historia/Instituto Nacional Indigenista, Colección Regiones, 1996, 1998.

BUCHILLET, Dominique. Chroniques d'une conquête. In: ETHNIES. Droits de l'Homme et Peuples Autochtones. Survival International, Paris, n. especial 14, 1993.

CASSIRER, Ernst. Mito y lenguaje. Ediciones Nueva Visión, Buenos Aires, Argentina [1 ${ }^{\mathrm{a}}$ ed. Alemana de 1925] 1973.

CHAGNON Napoleon A. Yanomamö: the fierce people. 4 ed. New York, Holt, Rinehart, and Winston, (1968) 1992.

CIMADAMORE, Alberto, Robyn EVERSOLE y John-Andrew McNEISH (Coord.). Pueblos Indígenas y pobreza: enfoques interdisciplinarios. Buenos Aires: CLACSO, 2006. 
CONEVAL. Informe de evaluación de la política de desarrollo social en México, Consejo Nacional de Evaluación de la Política de Desarrollo Social, 2012.

CONDE, Gerardo. La persistencia étnica de un grupo indígena: los guarijío. In: MIGUEL, Bartolomé (Coord.). Visiones de la Diversidad: relaciones interétnicas e identidades indígenas en el México actual, v. III, Instituto Nacional de Antropología e Historia, Serie Ensayos, México, 2005.

DA MATTA, Roberto. Mito e antimito entre os timbira. In DA MATTA, R. Mito e linguagem social: ensaios de antropología estructural, Rio de Janeiro, Ed. Tiempo Brasileño, 1979.

DESCOLA, Philipe. Más allá de naturaleza y cultura. Buenos Aires, Argentina: Amorrortu Editores, 2012. (2005 1 a ed. Francesa)

ELIADE, Mircea. Mitos, sueños y misterios. Buenos Aires, Argentina: Compañía General Fabril Editora, 1968. (Paris, Ed. Gallimard, 1956) (Hamburgo, 1957)

Lo sagrado y lo profano. Madrid: Ediciones Guadarrama, 1967. . Tratado de historia de las religiones, México: Ediciones ERA, 1972. (Paris, 1964)

FAUSTO, Carlos. Faire le mythe. Histoire, récit et transformation en Amazonie. Journal de la Société des américanistes, Paris, n. 88, 2002. GOSSEN, Gary. Los chamulas en el mundo del Sol. México: Instituto Nacional Indigenista, México, 1979.

HILL, Jonathan (Ed.). Rethinking History and Mith: Indigenous South American Perspectives on the Past. Chicago: University of Illinois Press, USA, 1988.

LEACH, Edmund. Lévi-Strauss, antropólogo y filósofo. Cuadernos Anagrama, Barcelona, 1970. (1 ${ }^{\mathrm{a}} \mathrm{ed}$. London, 1965)

LÉVI-STRAUSS, Claude. El pensamiento salvaje. México: Fondo de Cultura Económica, Breviarios n. 173, 1964. (1 ${ }^{\text {a }}$ ed. Francesa de 1962) (Paris, 1958)

Antropología estructural. Buenos Aires: EUDEBA, 1968a.

Lo crudo y lo cocido. México, FCE, 1968b. ( 1 a ed. Paris, 1964)

LÉVY-BRUHL, Lucién. El alma primitiva. Barcelona, España: Ediciones Península, 1968. ( (1ª ed. Francesa Galimard, Paris, 1927)

MELATTI, Julio César. O mesianismo krahó. São Paulo: Editora Herder, Unversidade de São Paulo, 1972. 
. A origen dos brancos no mito de Shoma Wetsa. Anuario

Antropologico, Universidade de Brasilia, DF, n. 84, 1985.

MONOD, Jean. Los piaroa. Boletín Informativo de la Asociación

Venezolana de Sociología, Caracas, n. 7, 1970.

PORRAS, Eugeni. Identidades y relaciones interétnicas en la Tarahumara. In: MIGUEL, A. Bartolomé (Coord.). Visiones de la Diversidad, Tomo I, INAH, 2005.

RIBEIRO, Darcy. Religião e Mitologia Kadiwéu. Rio de Janeiro, Publicação n. 106, Serviço de Proteção aos Indios, 1950.

. Os indios e a civilização. Rio de Janeiro: Editorial Civilização Brasileira, 1970.

SEBAG, Lucien. El mito: Código y mensaje, Cuadernos de Psicología, Buenos Aires, n. 1, 1968. ( $1^{\text {a }}$ ed. francesa Les Temps Moderns, n. 226, 1965)

SCHOUTEN, Ike Elisabeth. Yan Davi: el pueblo del rayo. Tesis de Maestría en Antropología, Universidad de Leiden, Holanda, 1991.

STEELE, Janet y Ralph Snavelly. Cueva Cheve Tablet. Journal of Cave and Karst Studies, University Of Texas, v. 59, n. 1, 1997.

TREJO, Leopoldo. Los senderos de la identidad zoque de Oaxaca. In: MIGUEL, Bartolomé (Coord.). Visiones de la Diversidad, México, v. II, INAH, 2005.

TALMON, Yonina. Milenarismo. Enciclopedia Internacional de las Ciencias Sociales, Madrid, v. 7, p. 104-113, 1975.

TURNER, Victor. Mito y símbolo. Enciclopedia Internacional de las Ciencias Sociales, v. 7. Madrid: Aguilar, 1975. (1968)

ULLÁN DE LA ROSA, Francisco Javier. La construcción del indio domesticado como categoría social y cognitiva. Revista Española de Antropología Americana, Madrid, v. 36, 2006.

VALLE, Julieta et al. Fuimos campesinos. Somos macehuales. In: MIGUEL, Bartolomé (Coord.). Visiones de la diversidad: relaciones interétnicas e identidades indígenas en el México actual. v. IV. México: Instituto Nacional de Antropología e Historia, 2005.

VARESE, Stefano. La sal de los cerros. Lima: Universidad Peruana de Ciencias Sociales, 1968.

VIVEIROS DE CASTRO, Eduardo. Os termos da outra historia/a historia en outros termos. In: RICARDO, C. A. (Ed.). Povos indígenas do Brasil. São Paulo: Instituto Sociambiental, 2000.

Recebido em 22/06/15

Aceito em 22/08/15 